\title{
28 Research Square \\ Dealing With Pluralism: Managerial Work of CEOs in Italian Public Healthcare Organizations
}

\section{Federico Lega}

Università degli studi di Milano

Andrea Rotolo

Bocconi University

Marco Sartirana ( $\triangle$ marco.sartirana@unibocconi.it )

Bocconi University

\section{Research Article}

Keywords: Hospitals, CEOs, managerial work, pluralistic organizations, Italy

Posted Date: November 17th, 2021

DOI: https://doi.org/10.21203/rs.3.rs-1062070/v1

License: (c) (i) This work is licensed under a Creative Commons Attribution 4.0 International License.

Read Full License 


\section{Abstract}

Background: Healthcare organizations are extremely complex, and the work of their CEOs is particularly demanding, especially in the public sector. However, we know little about how healthcare executives' managerial work unfolds. Drawing from scholarship on pluralistic organizations and managerial work, we answer the questions: what is the content of managerial work of executives in public healthcare? How do CEOs deal with pressures from internal and external stakeholders while maintaining a strategic agenda?

Methods: We adopted a mixed method with a survey to measure CEO behaviors, coding CEOs time for four weeks; a questionnaire to understand the strategic dimensions of interactions; interviews of senior CEOs.

Results: CEOs in Italian public healthcare devote most of their time to interactions, by and large responding to pressures by internal stakeholders. Although half of this time is perceived as occupied in answering operational requests, this is necessary to nurture relations, create networks and develop alliances and consensus, which are functional in achieving CEOs' strategic agenda.

Conclusions: CEOs in public healthcare must deal with enormous contextual pressures and cannot manage the complexity but are called to manage within the complexity, fostering involvement in decision making, building networks, and establishing alliances. Amidst ambiguity and fragmentation, executives need to find solutions to perform their managerial work without being entrapped by stakeholders' pressures, thanks to effective stakeholder management as well as delegation.

Trial registration: The article does not report the results of a health care intervention on human participants, and material used in the research did not need ethical approval according to Italian law.

\section{Introduction}

Managing healthcare organizations is highly complex as it requires to deal with powerful internal pressures, due to the presence of professionals claiming autonomy, and relevant environmental pressures, as numerous external stakeholders try to influence the strategic agenda $[1,2,3]$. Complexity increases in public healthcare organizations, which are called to balance managerialism and professionalism with accountability towards politics as well as relevant levels of red tape [4].

This puts a relevant pressure on healthcare CEOs, whose action and focus influences the strategic direction of the organization [5]. The scope of CEOs' work is vast, the number of internal and external interlocutors potentially countless and the constraints to an effective strategic action numerous. They are called to navigate in such complexity by performing their daily managerial work. However, although the role of CEO has been widely studied in healthcare management literature $[6,7,8]$ few empirical studies have studied the managerial work of healthcare CEOs, what they do in practice, and what type of activities take up his or her time. 
Research dates to the origins of managerial scholarship and to classics like Mintzberg's [9] study, which found, beyond the rhetoric of rational strategy making, that chief executives' work is fragmented, conducted at a relentless pace, and preferably through verbal interactions. Challenging conceptual and methodological advancements by recent analysis $[10,11,12,13]$ have shed some further light on the topic and explored how CEOs balance their time striving to advance a strategic agenda while being able to respond to everyday pressures from different stakeholders [14].

However, this scholarship, based on the quantification of activities, has also been critiqued for a lack of understanding of contexts and social relationships in everyday managerial work [15]. As a matter of facts, these studies mostly found common points in managerial action across time and sectors. This element is particularly relevant as, by arguing that managerial work in this sector would be not significantly distinct from other industries [13], it apparently contradicts the specificities of (public) healthcare.

Therefore, we draw from the literature on managerial work and the practice-based scholarship studying management in pluralistic contexts, in order to study what top managers actually do in public healthcare and what characterizes their work. Our research questions are what is the content of managerial work of executives in public healthcare? How do CEOs deal with pressures from internal and external stakeholders while maintaining a strategic agenda?

We analyze CEOs in the Italian National Health System, as they are professionals (mostly doctors) in charge of large healthcare organizations, called to exercise their strategic role responding to powerful internal and external stakeholder, exposed to strong political pressures, and bound to relevant bureaucratic constraints.

Our results show that CEOs in Italian public healthcare allocate time in ways that are comparable to CEOs of other sectors, and in line with what found by previous studies on managerial work, they devote most of their time to interactions, by large with internal stakeholders. Half of this time was perceived as occupied in responding to conflicting pressures and continuous requests from interlocutors. However, dealing with these requests is necessary to nurture relations and develop networks with key internal stakeholders, and to create alliances and build consensus with external actors. And this is key to establish effective collaborative decision-making processes that may enact change in a pluralistic organization.

In the following paragraphs we give a brief overview of the literature on strategic management in pluralistic contexts and on executives' managerial work. We then introduce the context and methodology of our study, which bridges quantitative and qualitative approaches. After presenting the findings of our analysis, we discuss them and the implications they may have for practice in healthcare services.

\section{Strategic management in pluralistic contexts}

Complex organizations characterized by tensions between divergent interests of groups, acting within the organization and in its environment, have been described as pluralistic contexts [16]. All organizations are 
pluralistic, but to different degrees. The highest level of pluralism is achieved when there are both strong internal pressures, as organizations must balance competing cultures and identities, as well as strong external pressures, as organizations must enact multiple and often contradictory strategies to respond to conflicting environmental demands [16].

These pressures result in difficult positions for executives. Top managers in pluralistic contexts must find complex solutions to couple leadership, organization and environment to permit change [2], and often excessive demands are placed on their time and attention which may overstretch their capacity [16]. Different solutions can be identified to meet these conflicting demands. Executives who are professionals themselves have the potential to perform a hybrid role $[17,18]$ reconciling more easily professional claims and managerial imperatives. Also, they can devote time to organize collective leadership constellations [19], i.e. top management structures in which multiple individuals combine their expertise and source of legitimacy in order to effectively deal with organizational complexity. As far as their managerial work is concerned, we know that CEOs must foster participation of a wide range of actors in decision-making processes and a collaborative approach towards stakeholders to navigate in such complexity [20,21]. However, we know little of what this means in practice and which implications it has on the managerial work of executives. The study by Jarzabkowski and Fenton [21] hints at examples of managerial actions capable to effectively address pluralism - including having frequent and close contacts with stakeholders to grant them recognition, ensuring that demands are met and placing fragmented interests in the wider organizational context - but provide little information regarding this. Our study aims at filling this gap by studying CEOs in public healthcare organizations.

As a matter of facts, the concept of pluralistic contexts is particularly appropriate for understanding the work of executives of public healthcare organizations, which are characterized by extreme levels of pluralism [22]. Internally, CEOs of public healthcare organizations must deal with complex professional, administrative and managerial cultures. First, they interact with powerful professionals [23], fragmented in various subcultures tied to medical specialties that have a legitimate stake in the formulation and implementation of a strategy to advance their specific goals. Though CEOs cannot exercise hierarchical power over professionals, they do need to align diverging goals, manage dissent and turf wars, and contend with power play in interactions with them [24] exercising political skills [25]. Under this respect, being a hybrid professional can help in mediating different cultures and contrasting expectations [18]. However, the balance of professional interests is just one of the internal challenges that public healthcare CEOs face. They also face more formal rules and higher levels of red tape, embedded in the public sector, and especially in the administrative staff $[26,27]$. Therefore, CEOs strive to reconcile at the same time professionalism, bureaucracy, as well as managerial logics and practices typical of New Public Management reforms [28].

At the same time CEOs face strong external pressures. As reported by Lega [4], CEOs in public healthcare organizations often receive vague, conflicting objectives from politicians and policymakers. The margin of autonomy that executives can enjoy within political constraints results from negotiation and wellmanaged relationships with key stakeholders such as public officials and policymakers. Also, they need 
to maintain the contacts with a variety of external stakeholders like local communities, media, private sector among others, whose demands can put enormous pressure on top managers' strategy and generate strategic ambiguity and uncertainty $[22,29]$.

With the aim to understand what characterizes the work of top managers in pluralistic contexts, i.e., what they do in their daily work, and study how they interact with different stakeholders, will draw from the literature on managerial work.

\section{The study of managerial work}

The study of managerial work is well established in organizational literature; the earliest reports date back to Fayol [30]. Reflecting on his personal observations as mining director, Fayol distinguished five functions of management: forecasting and planning; coordinating; organizing; commanding; and controlling. Building on this work, Gulick [31] coined the POSDCORB acronym for the main activities of a top manager: Planning, Organizing, Staffing, Directing, Co-Ordinating, Reporting, and Budgeting.

The work by Henry Mintzberg $[9,32,33]$ set the foundations for research; his approach has been replicated multiple times and remains a major point of reference [15]. Mintzberg [9] applied an empirical and an inductive approach to studying how top managers use their time. He critiqued the work of Fayol and, after describing the actual morning routine of a top manager, he asked, "Which of these activities may be called planning, and which may be called organizing, coordinating, and controlling? Indeed, what do words such as 'coordinating' and 'planning' mean in the context of real activity? In fact, these four words do not describe the actual work of managers at all" [32: 97]. He directly observed a CEO's activity for one week and analyzed the verbal contacts, the location of verbal contacts, the size of meetings, the participants attending the meetings, and the purpose of contacts. He found that, in contrast with theories about a CEOs' focus on strategic programming, the activity of a top manager is highly fragmented and much time is spent dealing with emerging day-to-day problems rather than on long-term issues. He noted in particular that CEOs devote a surprisingly large amount of time to verbal rather than written interactions. Almost half of the meeting time referred to encounters with subordinates, while the rest of the time was devoted to superiors, co-directors, and external clients/suppliers.

His work had a huge impact on later research [34]. Kurke and Aldrich [35] corroborated Mintzberg's findings in their study. Tengblad [10] returned to the work of Mintzberg to question whether managerial work had undergone radical change over the decades, in parallel with the evolution in the managerial rhetoric towards non-hierarchical, more flexible forms of organization and greater emphasis on the top manager as a leader. He found that, although a relative shift in CEO behavior from administrative management to leadership can be envisioned, most of Mintzberg's findings were still valid. The few exceptions were that a CEO's work was less fragmented and interrupted, overall workload was heavier, time spent doing desk work was less, while more time was spent attending ceremonies. The same methodology was adopted to study CEOs of Canadian public healthcare organizations by Johnson and Dobni [13], who compared their findings with previous studies arguing that high-level managerial work in the public sector is similar in many ways to that of private sector, and therefore present "evidence that 
indicates that managers may be transferrable across sectors... [and] that private sector managers can easily step into public roles due to parallels in tasks and responsibilities" [13: 467].

Alternative methodological approaches were adopted by Bandiera et al. [12] who, with the aim to determine whether differences in CEO behavior have implications for a company's performance, developed a methodology to collect data on how CEOs used their time. They recorded the type of activity, planning horizon, number of participants and functions via CEOs' diaries over one week and via daily phone calls with them or their personal assistants. Based on the data collected from a large sample of CEOs working in different countries and sectors, they found that CEOs spend $70 \%$ of their time interacting with others, especially with insiders (e.g., production and marketing staff, etc.) and $20 \%$ with outsiders (e.g., clients, suppliers, consultants). Porter and Nohria [14] adopted a similar approach in which they asked the executive assistants of CEOs to code the duration of their boss's activity in 15-minute segments, 24 hours a day, seven days a week, and to check with their boss that the recorded activity codes were correct. The results were then discussed with the study participants. Furthermore, they introduced a complementary dimension of analysis, asking CEOs' how much time was devoted to the core agenda, and how much was spent in a reactive mode, handling unfolding issues, both internal and external, and in dealing with have-to-dos, in line with the distinction between management and leadership [e.g. 36]. In this, they imply that CEOs should delegate operational tasks to managers to free up time for activities more related to their strategic agenda.

These studies were aimed at finding commonalities across the action of mangers, and as a matter of facts, differences in epochs and approaches notwithstanding, they found rather similar patterns of how CEOs used their time as regards the type of work activity.

However, despite their large diffusion, these approaches have been critiqued as they don't allow a contextualized understanding of managerial work. With a few exceptions [e.g., 24], most studies have examined managerial work separate from its institutional context and maintained and analytical focus on individuals or jobs rather than on relational practices [15]. Therefore, authors like Noordegraaf and Stewart [37: 440] claimed that it is necessary to study the "social embeddedness of managerial behavior", and Korica et al. [15] argued that, in order to bring "managerial work back to the future", a turn towards practice approaches is necessary, shifting the analytical focus towards social relationships, discursive processes and situated realities of everyday managerial work. Accordingly, they underline the limits of methods based on the quantification of activities, arguing the necessity to substitute or complement them with rich qualitative approaches capable of explaining managers' actions and interactions.

In line with these studies, we combine the traditional research approach on managerial work with a more practice-based lens capable to bring relations and context back in the analysis of work of executives and to take into account the specificities of a public healthcare sector and the challenges of dealing with strong internal and external pressures. This will allow to better understand the managerial work of CEOs in pluralistic contexts. Also, it will offer a contribution to the debate on managerial work, showing whether findings from public healthcare differ or not from evidence found in other sectors. 


\section{Setting}

The present study reports the findings from an analysis of the managerial work of CEOs in public healthcare organizations in Italy. The Italian National Health Service (NHS) is organized by the 20 regional governments and coordinated by the Ministry of Health. The regional government

administrations define the health policies and the structure within regional competencies and they assign to public and private providers the goals and targets of outputs and/or clinical outcomes. There are three types of public healthcare organizations: Local Health Authorities for the delivery of hospital care as well as primary care and public health services; hospital trusts that deliver hospital care (some of them can also be teaching hospitals); and research hospitals. On average, public healthcare organizations have nearly 1100 beds and over 3000 employees [38]. The CEOs heading public healthcare organizations are appointed by the regional governor based on a spoils system method. CEO performance is evaluated by the Regional Health Authority according to annual targets, and their mandates cannot exceed the regional governor's mandate of five years; the length a CEOs' mandate is 3.7 years on average [38]. More than two thirds of CEOs are physicians, most of which have a specialization in public health and hospital management, and this is considered helpful in understanding clinical issues and in interacting with professionals [39]. CEOs are supported by a Medical Director and an Administrative Director (this triad is usually referred to as the strategic board), and in some cases by a Director for social care and a Nurse Director.

\section{Methods}

As anticipated, variety of methodologies have been developed to study managerial work, from in-depth observational analysis of a few cases to large-scale quantitative analysis of the agenda of CEOs. Depending on the research objectives, the approaches opt for diverse solutions to the trade-off between sample size and depth of research. For the present study, building on existing literature we adopted a mixed method with a four-step approach, designed to reach a comprehensive knowledge of the distribution of time of CEOs and the interpretation they provide to the type of activities carried out during their working days.

First, we developed a survey tool to measure CEO behaviors, based on two sections of the tool described in Bandiera et al. [12]. The categories were: Type of activity (meetings, conference calls and business lunches; individual work; public events/ceremonies; travelling; continuing professional education; personal/family) and Type of interlocutor in the meetings. Based on the authors' experience in the Italian $\mathrm{NHS}$, we identified the main internal and external interlocutors that interact with CEOs: regional government administrators, CEOs from other public healthcare organizations, administrative/medical director, administrative staff, healthcare professionals, local government administrators and community leaders, trade union representatives, patient associations, industry, press/media, other (university, etc.). The tool was tested with two CEOs and revised according to their feedback comments. 
Second, we asked executive assistants of CEOs to code their boss's work time in 30-minute segments, seven days a week for four consecutive weeks (the period chosen was March 2019) retrieving data from the calendar of CEOs and to check the code with their boss. The questionnaire was sent to all CEOs $(n=194)$ in Italian public healthcare organizations. The response rate was $20 \%(38 / 194$, from nine regions), which we deemed appropriate considering the difficulty in accessing CEOs and the effort requested to them and their assistants. 20 respondents are CEOs of independent large public hospital trusts (including some teaching hospitals), while 18 are CEOs of Local Health Authorities, all including secondary care facilities. These organizations are mostly based in Northern Italy (79\%), have an average of 800 beds, 3,800 employees and a turnover of 600 million euros (approximately 720 million US dollars).

As a third step, we sent one month later a second questionnaire to the 38 CEOs asking them to verify the results of the first questionnaire (a table showing the results from the coding made by the executive assistants for each CEO was made available to check) and to indicate the amount of time they worked that was not on the formal agenda or calendar (e.g., at night the weekend). In line with Porter and Nohria [14], we asked the CEOs to specify how much the time spent in meetings with interlocutors was devoted to the strategic agenda ("strategic time", explained as "directly connected with the goals of their mandate and their organization's medium or long range objectives, as defined in strategic documents"), and what portion was devoted to handling unfolding issues and dealing with have-to-dos (explained in the questionnaire as "operational time or time related to unplanned requests by different stakeholders"). Of the 38 CEOs contacted, 17 (45\%) participated in this third phase. The sample can be considered as representative since CEOs who have answered to both questionnaires have a relevant experience as CEOs (also in other organizations; average experience is 5.7 years for the first questionnaire and 5.5 years for the second) or as member of strategic boards in public healthcare organizations (average experience is 10.4 years for the first questionnaire and 11.3 years for the second) and could provide an interpretation of their role based also on those experiences in other organizations and regional contexts. Male CEOs account for $85 \%$ for the respondents of the first questionnaire and $88 \%$ for the second; average age is 58.5 and 58.6. The characteristics of the sample are consistent with a previous study conducted among public healthcare organizations in Center and Northern Italy in 2013 [40] where the average age of CEOs was 59 years, male CEOs were $85 \%$, and the average experience as members of strategic boards in healthcare organizations was 11 years. Table 1 shows the characteristics of the two samples. 
Table 1

- Characteristics of the sample

\begin{tabular}{|lll|}
\hline & $\begin{array}{l}\text { Questionnaire 1 } \\
(\mathbf{N}=38)\end{array}$ & $\begin{array}{l}\text { Questionnaire 2 } \\
(\mathbf{N}=17)\end{array}$ \\
\hline Average age & 58.6 years old & 58.5 years old \\
\hline$\%$ Male CEOs & $84 \%$ & $88 \%$ \\
\hline Average experience as CEO in the organization & 2.4 years & 3.1 years \\
\hline Average experience as CEO (also in other organizations) & 5.7 years & 5.5 years \\
\hline $\begin{array}{l}\text { Average experience as member of strategic boards in } \\
\text { healthcare organizations }\end{array}$ & 10.4 years & 11.3 years \\
\hline
\end{tabular}

Fourth, with the goal of achieving a more nuanced understanding of executives' managerial work, we completed the analysis with ten interviews with experienced senior or retired CEOs (who had served in multiple healthcare organizations [3.7 organizations on average, and in different regions]), asking them to comment on the overall results and to provide a narrative account of the time they spent with internal and external interlocutors on the core agenda. The choice of involving senior or retired CEOs (a different sample from the one who completed the questionnaires) was made to provide an external and additional contribution to interpret evidence collected, also checking if evidence was consistent with the experience of top managers who have worked for a significant number of years at executive levels of public healthcare organizations. Interviews were conducted in person or online and were anticipated by sending to interviewees a summary of the results of questionnaires.

On the basis of our theoretical framework and the literature on pluralistic organizations, we defined a topic list of open-ended questions, fine-tuned after a pilot interview. Respondents were asked to report on what does the CEO do to maintain a strategic agenda while interacting with each of the main stakeholder, and to provide concrete illustrations from their professional experience. Furthermore, we asked interviewees if, based on their experience as CEO in various healthcare organizations, they agreed with the questionnaire results. Interviews were held in Italian, consent to participate was provided by all participants prior to the beginning of the research, and anonymity and confidentiality of participants were guaranteed. Interviews were summarized with the aim to condense findings emerging from respondents [41].

The initial conceptualization of the qualitative data was done by identifying relevant concepts in the empirical material, using CEOs' perspectives as the starting point of the analysis and using a constant comparison technique. Based on the words expressed by interviewees, when corroborated across multiple informants, two of the three authors developed categories emerging from data, which were then discussed and developed with the third author. Data interpretation was then developed through an iterative process from data to theory on managerial work in pluralistic contexts. 


\section{Results}

\section{Quantitative analysis}

First of all, the analysis of the diaries showed that the CEOs are engaged in different types of activities for 50.3 hours per week on average. If we exclude the time coded as dedicated to private life commitments during regular working hours (e.g., medical examination, domestic obligations, etc.) and we add the number of hours of additional work performed at home ( 5.5 hours per week), Italian CEOs spend a total of 52.7 hours per week on managing their healthcare organization. More than half of time $(56 \%$, or 28.3 hours per week) is spent in meetings, mainly face-to-face. Some $23 \%$ of the time ( 11.5 hours per week) is used for individual work (preparing documents, reading, sending e-mails, etc.). Such work is often interrupted by unplanned calls or other activities. Participation in public events (conferences, workshops, inaugurations, etc.) takes up, on average, 4.1 hours per week ( $8 \%$ of total time), while $5 \%$ ( 2.4 hours per week) is spent travelling for work, and only $2 \%$ ( 1 hour per week) is devoted to continuing professional education.

Evidence from the diaries discloses a more detailed picture on how they spend their time in meetings and interactions. 2.7 hours per week (5\% of total time) are spent with regional government administrators, CEOs' superiors, while 6.4 hours per week in interactions with other members of top management (strategic board members including the administrative director and the medical director), CEOs' coleaders. Most meetings are with internal stakeholders: 7.2 hours per week ( $14 \%$ of total time) are spent in discussions with healthcare professionals working for the organization, 6 hours (12\%) in meetings with staff members of the organizational technostructure (i.e., administrative staff and other managerial or bureaucratic support roles) and 1.2 hours (2\%) with union representatives. As regards external stakeholders, 1.6 hours (3\%) with local government administrators, and 1 hour (2\%) with CEOs from other healthcare organizations. Interaction with representatives from patient associations, media, pharma and medical technology companies, and other stakeholders takes a smaller proportion of time. Table 2 presents the amount of time spent in various activities per week.

Interestingly, these data are pretty much aligned with previous studies on CEOs in both the private and public sector, with specific reference to the share of time allocated to the different activities and the how interaction time is allocated to different interlocutors. One of the differences is the average work week of 52,7 hours which, although it is not significantly different from Johnson and Dobni [13] results, is indeed much shorter than what found by studies in the private sector. Also, time devoted to transportation is also significantly lower than what found in other studies, probably due to the limited geographic extension of Italian public healthcare organizations if compared to large companies from other industries. Lastly, the time spent in interactions with clinicians is much higher than the one registered by Johnson and Dobni [13] in their study of healthcare CEOs: $14 \%$ versus $8 \%$.

Table 2 - Weekly amount of time of healthcare organization CEOs (activities and interlocutors). N=38 


\begin{tabular}{|lll|}
\hline Activity & Hours/week & \% of time \\
\hline Meetings & 28.3 & 56 \\
\hline with regional government (superiors) & 2.7 & 5 \\
\hline with strategic board members (co-leaders) & 6.4 & 13 \\
\hline with internal stakeholders & 14.4 & 28 \\
\hline Professionals & 7.2 & 14 \\
\hline Organizational technostructure & 6.0 & 12 \\
\hline Union representatives & 1.2 & 2 \\
\hline with external stakeholders & 4.9 & 9 \\
\hline Local governments & 1.6 & 3 \\
\hline Other CEOs & 1.0 & 2 \\
\hline Patient associations & 0.7 & 1 \\
\hline Media / press & 0.6 & 1 \\
\hline Pharma and MT[1] companies & 0.2 & 0 \\
\hline Other Stakeholders & 0.8 & 2 \\
\hline Individual work (coded in the diary) & 11.5 & 23 \\
\hline Public events & 4.1 & 8 \\
\hline Business trips & 2.4 & 5 \\
\hline Continuing professional education & 1.0 & 2 \\
\hline Family and private life (coded in the diary) & 3.0 & 600 \\
\hline Individual work (not coded in the diary) & 5.5 & 52.7 \\
\hline Total & & \\
\hline
\end{tabular}

In a following step, in order to deepen the analysis, we asked the CEOs to evaluate the amount of time they spent in meetings they perceived as relevant for achieving their strategic goals and how much time they perceived as being invested to address operational requests. As reported in Table 3, most of the time invested in meetings is perceived as "strategic", especially when the counterpart is the regional government (76\%), the strategic board (69\%), and the CEOs from other healthcare organizations $(63 \%)$. However, this is the case for nearly half of the time of interactions with other internal (healthcare 
professionals, union representatives and organizational technostructure and) and external (local communities, patient associations, providers) stakeholders.

Table 3 - Strategic relevance of meetings. $\mathrm{N}=17$

\begin{tabular}{|ll|}
\hline Meetings with & \% perceived as "strategic" \\
\hline Regional government administrators & 76 \\
\hline Strategic board members & 69 \\
\hline CEOs from other healthcare organizations & 63 \\
\hline Local communities & 58 \\
\hline Union representatives & 52 \\
\hline Patient associations & 50 \\
\hline Organizational technostructure & 49 \\
\hline Healthcare professionals & 48 \\
\hline Pharma and medical technology companies & 48 \\
\hline Press / media & 36 \\
\hline Other stakeholders & 42 \\
\hline Total & 56 \\
\hline
\end{tabular}

\section{Qualitative Analysis}

Dealing with internal pressures: pampering and fostering consensus.

The final step was to carry out interviews with experienced senior or retired CEOs who assisted the research team in sense-making of the results and in analyzing the role of CEOs in public healthcare organizations. Understanding how they work on the strategic agenda while responding to pressures from internal and external stakeholders shows how managerial work is actually performed, as influenced by context and relations.

The vast majority of CEOs' time and efforts devoted to dealing with internal pressures. Interviewees reported the importance of nurturing the interaction with professionals, "pampering" them as they must be listened to and involved in decision making in order to overcoming resistance to change by providing constant stimuli. Furthermore, hospitals are professional organization, and to foster collaborative approaches that reduce fragmentation between professional and the administrations and across professional subgroups, CEOs are engaged in developing internal networks. This requires a relevant 
investment of time also in very informal chats, or in activities that might appear operational or mundane, but that need to be faced to avoid that they degenerate into larger distractions if the CEO does not attend to them.

"Professionals must be pampered and stimulated, the relationship with them is fundamental and takes a lot of hours. You need to talk to professionals about data on a monthly basis, at least with the most important ones". (CEO \#8)

"I personally managed the budget meetings to get to know professionals, to understand the internal dynamics; I observe that often they simply need to be listened to and they need recognition, and I think it is appropriate to dedicate good part of my time in this activity which can foster a good corporate climate and nurture a sense of belonging to the group". (CEO \#7)

"Sometimes I call them, but very often they are looking for me. I often meet unit directors and professors because I want to hear how the hospital is going, and I don't want my knowledge to be filtered only by my staff. This is not really separate [from strategy making], an informal exchange with a professional can have strategic significance". (CEO \#6)

Also, internal pressures derive from the fact that, being a public organization, professionals - not only doctors but also nurses and other health staff - are strongly backed by trade unions are extremely influential and need careful attention and involvement.

"Today the greatest amount of time of a CEO is spent in relationships, with professionals and their spokespersons, generally trade unionists. And in this relationally complicated context, each of us has to work to create networks... everyone is entrenched, protects their fort, and the CEO must put him int the net: this is the challenge that occupies $40 \%$ of my work" (CEO \#4).

"Dealing with trade unions is very difficult as they have a very strong ability to slow down any reorganization project, and capacity for blackmail using vexatious tools, if it is not possible to find an agreement which is favorable to them" (CEO \#5).

Furthermore, the administrative staff requires interaction on various managerial as well as bureaucratic issues which must be dealt with.

"The problem is that [administrative staff] tend to draw the work of the CEO on their issues, and they frequently confuse the means with the ends; the CEO must direct the staff, not follow them" (CEO \#1).

Sometimes CEOs balance relationship building with the need to take unpopular decisions by triangulating with the Administrative or the Medical Director, the members of the strategic board. Therefore, the work of top managers is not individualistic, rather it is collegial and performed with the support of people who help the CEO in balancing different perspectives, interests, pressures and demands. Building a cohesive strategic board was considered a key issue, and as a matter of facts $69 \%$ of the time spent with them was defined strategic. 
"If the goal is 10 and the professional makes 7, I involve the Medical Director to ask the professional to do 12. Then the professional comes to me and I mediate. We use the tactic of the good cop and bad cop". (CEO \#8)

Dealing with external pressures: building alliances and developing consensus

As for managing the environmental complexity and external pressures, the CEO must of course interact with their superiors, national and regional policymakers. However, in the absence of a board dedicated to the relationships with the community, as it happens in other countries [e.g. 1], the CEO is called to develop partnerships and alliances with politicians, as well as with local municipalities, patient associations and other representatives of the civil society, and to manage relationships in order to develop consensus achieving the support from key stakeholders. These relationships account for a relative smaller percentage of the CEOs' time, but require time in order to avoid the risk of escalation of problems.

"Frequent relationship both with the formal representatives of the communities and with the citizens' groups [are important], in order to explain how much they are involved in the strategies [of the hospital] and in the technical choices made to pursue them. Direct confrontation, transparency and consistency have more often yielded positive results than avoiding the encounter" (CEO \#9).

"Relations with mayors and associations are fundamental, perhaps they are the most important ones: we need to increase the forms of "alliance", for example organizing joint events: conferences, training events, information campaigns" (CEO \#1).

"Patient organizations are important partners and sometimes it is important that the CEO is there to meet them, especially some categories more in need or more relevant in the area (e.g. paraplegics, dialysis patients), otherwise situations that could be avoided explode for nothing" (CEO \#3).

The relationship with press and media is interesting as it is perceived as the strategically least relevant stakeholder. A plausible explanation for this low ranking is that the media and journalists reporting on healthcare in Italy are generally perceived as having neither the necessary standing nor the capacity to be engaged in strategic management processes, though they obviously need to be operationally "managed" to avert bad press.

"It would be very strategic to have the media as partners for the dissemination to the population of strategies and choices, and to explain how to make appropriate use of services and resources. However, as it happens with unions, the media are much more often scoop-oriented, especially looking for negative stories" (CEO \#9).

\section{Footnote:}

[1] Medical Technology

\section{Discussion}


Our findings allowed to answer our research questions on what characterizes CEOs' managerial activity in pluralistic contexts and how they strive to maintain their strategic agenda while responding to internal and environmental pressures.

First, data showed that CEOs' time is mainly spent in interactions, dealing with pressures from internal and external stakeholders. Nearly half of this time was perceived as non-directly related to strategic agendas, and rather occupied in answering operational requests and dealing with apparently mundane have-to-dos. At a first sight, this could be read as a signal that CEOs might be better at delegating tasks to co-leaders to free up time for strategic activities and overall steering of the organization. Following Kotter's [36] distinction, CEOs would be supposed to perform leadership - i.e., coping with change - while delegating management - i.e., coping with complexity - to the other members of the strategic board. However, as shown by the qualitative analysis, our results reveal some of the main features of the managerial work of public healthcare executives called respond to conflicting pressures and continuous requests from different stakeholders. CEOs nurtured relationships with key stakeholders, invested time in listening to their requests and needs, often in informal ways, manifested genuine understanding and provided operational support, being highly visible and directly involved. They were aware that they had to be ready to take care of uprising problems that might appear insignificant but, if not considered, could evolve in more serious problems or compromise relationships. Therefore, to a relevant degree, in pluralistic contexts the distinction between leadership and management fades, as change can be achieved only by dealing with the complexity. CEOs' heavy investment of time and energies in daily interactions with stakeholders was functional to creating relational networks and building consensus, necessary for establishing effective collaborative decision-making processes that may enact change. This is particularly coherent with the complexities which characterize the healthcare sector, and in particular the Italian NHS, in which there is a tremendous need to reduce fragmentation and foster integration, both internally, across disciplines and professional groups, and externally, across healthcare providers that participate in patients' care pathways [28]. And this is even more relevant in our context of public healthcare, where CEOs faced red tape and constraints to the development of effective managerial tools and cultures in organizations largely dominated by bureaucratic approaches. On the one hand, they needed to interact with administrative and technical support staff and middle managers within the organization which had limited managerial competencies. On the other hand, they needed to master a vast number of rules and regulations, as seemingly inefficient time spent in understanding the legal/normative configuration of a problem could turn out to be extremely effective. Therefore CEOs, rather than aiming at managing the complexity, which would also be not achievable, should be able to manage within the complexity [42].

At the same time, there a risk in this approach. Even if they are loath to admit it, CEOs may prefer operational time because it's problem-solving time. And incompetent CEOs might more easily hide ineffective managerial behaviors behind an apparent commitment to operational activities. Therefore, they should be able to identify defensive maneuvers which prevents them from performing a CEO's managerial work. Otherwise, the agenda will be only based on urgencies, and the absence of a strategic direction could produce incapacity to produce change or paralysis $[2,22]$. 
Secondly, a relevant share of time was devoted to interactions with the members of the board, and this time was particularly aligned to the strategic agenda. This supports previous findings on the importance of building an effective role constellation to deal with internal and external pressures, often triangulating, as shown in the interviews. The hybrid nature of most of the Italian CEOs, who are doctors themselves, definitely facilitates the bridging of professional and managerial worlds. However, also in this case, leadership is necessarily distributed and shared with the other components of the strategic apex. Accordingly, health systems should support the development of co-leadership and effective delegation mechanisms [19] to deal with such complexity.

Thirdly, building on existing literature from different perspectives, we have adapted and developed a quali-quantitative methodology to measure how healthcare CEOs use their time, contributing to answer the call by Korica and colleagues [15] to take into account the context of managerial work and its relational dimension. We believe that this approach, which allows to capture managerial work activities as well as the strategic dimension of interactions with different stakeholders, may be replicated comparing CEOs in different organizations and across various healthcare systems.

Finally, we believe we can better understand what top management in public healthcare really is, the commonalities it shares with other sectors, and in what ways it differs from them. We argue that, despite our quantitative findings showed many similarities to results obtained in other sectors [e.g. 10, 14], our overall analysis underlined the peculiarities of CEOs' managerial work in pluralistic contexts like public healthcare, therefore contradicting Johnson and Dobni [13] when they claim that similarities prevail and, accordingly, managers may be transferrable across sectors.

Of course, this work has also various limitations. Although our response rate is satisfying considering the effort required to CEOs and their assistants, the sample is relatively limited. Larger samples may allow to control for different contextual factors that might impact on CEOs' time allocation. Moreover, CEOs and their assistants were asked to describe the distribution of their time for one month, but we are aware that there might be seasonality in the allocation depending on the period of the year or on the phase of the managerial mandate. Observing a longer period could provide more insights on the characteristics of managerial work performed by CEOs of public healthcare organizations. Furthermore, our data were collected form CEOs of public healthcare organizations within a NHS, while a richer picture could be captured by studying executives working in other countries with different health systems. Comparative research might provide precious contributions to our understanding of managerial work in (public) healthcare and how it is influenced by institutional and regulatory factors (including specific organizational structures or boards supporting the CEO) as well as by organizational features. Furthermore, it may give relevant information to design effective educational programs that account for these specificities.

\section{Conclusions And Practice Implications}


According to the results of our study, executives in pluralistic organizations in public healthcare seem to be burdened by three major problems. The first one is the struggle to use wisely the time, finding a balance between working hours for operational activities and time invested in strategic activities. It would be a myth thinking that top managers could focus only on issues of the strategic agenda, as he or she is called to respond to continuous pressures from stakeholders by listening to them, showing understanding, involving in decision making. Therefore, interaction on apparently mundane and operational problems, informal chats, network building activities are necessary. The complexity of healthcare makes the pressure of operational tasks extremely significant, and we agree with Mintzberg [9] in that a CEO's activity is necessarily highly fragmented and faces emerging day-to-day problems rather than long-term issues.

However, such complexity and ambiguity should not be used an excuse for devoting all the energies to operational time. As a matter of facts, making decisions is more attractive than designing the future, it is usually what CEOs studied for and it is what generates short-term self-realization. Patients, emergency department pressures, bureaucratic human resources problems can't wait. Changes and innovations can. Therefore, they should avoid the risk of being entrapped by the pressures of stakeholders, resulting in inadequate capacity to perform executives' managerial work.

A third issue regards delegation. Our study suggests that for CEOs of public healthcare organizations, also when they are hybrid themselves, external support is necessary to respond to pressures from multiple stakeholders. It is important to build strong strategic boards with complementary capabilities. In the context of the Italian NHS, Administrative and Medical Directors withing public healthcare organizations may be in charge of specific aspects of the managerial work required, for instance dividing the focus of each member of the strategic board between those who should be more focused in internal matters (e.g., Medical Directors) and who should be more engaged with external stakeholders (possibly the CEOs). More broadly, CEOs should delegate responsibilities not only to other top managers, but also to middle level managers and clinical leaders. However, this is not easy, as it requires developing trust, giving up power, training managerial competences of physicians when lacking [43]. And CEOs might not have the willingness of capacity to do so.

Health organizations urgently need CEOs engaged in navigating present challenges and paradigm shifts on the horizon. There are dramatic changes ahead in the delivery of health services. Research may help to shape better knowledge about the practices CEOs in healthcare organizations will need to perform strategy making within complexity. This may open new avenues for future research and lay the basis for a much-needed redesign of the training content for CEOs in healthcare organizations.

\section{List Of Abbreviations}

CEO

Chief Executive Officer

$\mathrm{NHS}$ 


\section{Declarations}

Ethics approval and consent to participate: Informed consent to participate was provided by all participants prior to the beginning of the research. All interviewees were informed regarding the purpose of the study, research details, funding source as well as expected outputs. The article does not report the results of a health care intervention on human participants, therefore the material used in the research did not need ethical approval in Italy. The Code of conduct for the use of data for scientific purposes of the Italian Privacy Authority (https://www.garanteprivacy.it/web/guest/home/docweb/-/docwebdisplay/docweb/1556635), which applies to all non clinical scientific research (art 2), does not require approval from an Ethical Committee. All methods were performed in accordance with the relevant guidelines and with the Declaration of Helsinki.

Consent for publications: Not applicable.

Availability of data and materials: The dataset used during the current study are available from the corresponding author on reasonable request.

Competing interests: We do not have any competing interests.

Funding: The study was funded by CERGAS Bocconi within the OASI Observatory on the Italian Health System.

Authors' contribution: Each author participated in the design of the research, interpretated the results and substantially revised the manuscript to reach the last version of the paper. All authors read and approved the final manuscript. FL conceived the study, contributed to defining the methodology, performed some of the interviews and wrote the conclusions. AR drafted the questionnaire, performed part of the data collection, contributed to writing the findings and discussion sections. MS contributed to drafting the questionnaire, performed part of the data collection, carried the literature review and wrote the background and methods sections, as well as part of the findings and discussion sections.

Acknowledgements: Not applicable.

\section{References}

1. Glouberman S, Mintzberg H. Managing the care of health and the cure of disease-part l: differentiation. Health Care Management Review, 2001;26(1), 56-69.

2. Denis JL., Langley A, Rouleau L. Strategizing in pluralistic contexts: Rethinking theoretical frames. Human Relations, 2007; 60(1), 179-215.

3. De Bruijn JA. Managing Professionals. London: Routledge. 2010. 
4. Lega F. Beyond rhetoric, inquiry on the essence of strategic management in public healthcare organisations. The International Journal of Clinical Leadership, 2012;17, 175-84.

5. Ocasio W. Towards an attention-based view of the firm. Strategic Management Journal, 1997;18, 187-206.

6. Liang Z, Howard P, Wang J, Xu M, Zhao M. Developing senior hospital managers: does 'one size fit all'? - evidence from the evolving Chinese health system. BMC Health Services Research 2020 20:281.

7. Ford EW, Lowe KB, Silvera GB, Babik D, Huerta TR. Insider versus outsider executive succession: The relationship to hospital efficiency. Health Care Management Review, 2018;143(1), 61-68.

8. Mascia D, Piconi I. Career Histories and Managerial Performance of Health Care CEOs: An Empirical Study in the Italian National Health Service. Health Care Management Review, 2013;38(1), 71-80.

9. Mintzberg H. The Nature of Managerial Work. New York, NY: Harper \& Row. 1973.

10. Tengblad S. Is there a 'New Managerial Work'? A comparison with Henry Mintzberg's classic study 30 years later. Journal of Management Studies, 2006;43, 1437-1461.

11. Bandiera O, Guiso L, Prat A, Sadun R. What do CEOs do? EIEF Working Paper. 2011.

12. Bandiera O, Hansen S, Prat A, Sadun R. CEO behavior and form performance. Working Paper 23248, National Bureau of Economic Research. 2017.

13. Johnson B. Dobni D. Is Managerial Work in the Public and Private Sectors Really "Different"? A Comparative Study of Managerial Work Activities. International Journal of Public Administration, 2016;39:6, 459-469.

14. Porter M, Nohria N. How CEOs manage time. Harvard Business Review, 2018;96(4), 42-51.

15. Korica M, Nicolini D, Johnson B. In Search of 'Managerial Work': Past, Present and Future of an Analytical Category. International Journal of Management Reviews, 2017;19, 2, 151-174.

16. Jarzabkowski P, Fenton E. Strategizing and Organizing in Pluralistic Contexts. Long Range Planning, 2006;39 (6), 631-648.

17. Denis JL, Ferlie E, Van Gestel N. Understanding Hybridity in Public Organizations. Public Administration, 2015;93 (2), 273-289.

18. Sarto F, Veronesi G. Clinical leadership and hospital performance: assessing the evidence base. BMC Health Services Research, 2016;16(2), 85-97.

19. Denis JL, Lamothe L, Langley A. The Dynamics of Collective Leadership and Strategic Change in Pluralistic Organizations. Academy of Management Journal, 2001;44, 4, 809-837.

20. Denis JL, Langley A, Cazale L. Leadership and strategic change under ambiguity. Organization Studies, 1996;17(4), 673-699.

21. Jarzabkowski P, Balogun J. The practice and process of delivering integration through strategic planning. Journal of Management Studies, 2009;46(8), 1255-1288.

22. Cuccurullo $C$, Lega F. Effective strategizing practices in pluralistic settings: the case of academic medical centers. Journal of Management and Governance, 2013;17(3),609-629 
23. Gilmartin MJ, D'Aunno TA. Leadership Research in Healthcare. The Academy of Management Annals, 2007; 1:1, 387-438.

24. Dargie, C. Observing chief executives: analysing behaviour to explore cross-sectoral differences. Public Management and Money, 2000;July-September, 39-44.

25. Clarke JM, Waring J, Bishop S, Hartley J, Exworthy M, Fulop NJ, Ramsay A, Roe B. The contribution of political skill to the implementation of health services change: a systematic review and narrative synthesis. BMC Health Services Research. 2021;21(1), 260.

26. Rainey HG, Bozeman B. Comparing public and private organizations: Empirical research and the power of the 'a priori'. Journal of Public Administration Research and Theory. 2000;10(2), 447-470.

27. Orazi DC, Turrini A, Valotti G. Public sector leadership: new perspectives for research and practice. International Review of Administrative Sciences, 2013;79(3), 486-504.

28. Lega F, De Pietro C. Converging Patterns in Hospital Organisation: Beyond the Professional Bureaucracy. Health Policy, 2005; 74(3), 261-281.

29. Lega F, Longo F, Rotolo A. Decoupling the use and meaning of strategic plans in public healthcare. BMC health services research, 2013;13(1), 1-11.

30. Fayol, H. General and Industrial Management. London: Pitman. 1916.

31. Gulick L. Notes on the theory of organization. In Gulick, L., Urwick, L. (Eds.), Papers on the Science of Administration (pp. 1-45). New York: Columbia University Press. 1937.

32. Mintzberg H. Managerial work: analysis from observation. Management Science, 1971;18, 97-110.

33. Mintzberg H. Managing. San Francisco, CA: Berrett-Koehler. 2009.

34. Tengblad S, Vie OE. Management in practice: overview of classic studies on managerial work. In Tengblad, S. (Ed.), The Work of Managers: Towards a Practice Theory of Management (pp. 18-44). Oxford: Oxford University Press. 2012.

35. Kurke L, Aldrich H. Mintzberg was right: A replication and extension of the nature of managerial work. Management Science, 1984; 29, 975-984.

36. Kotter JP. The leadership factor. New York, NY: Free Press. 1987.

37. Noordegraaf $M$, Stewart R. Managerial behaviour research in private and public sectors: distinctiveness, disputes and directions. Journal of Management Studies, 2000; 37, 427-443.

38. Cinelli G, Gugiatti A, Meda F, Petracca F. La struttura e le attività del SSN. In CERGAS (Ed), Rapporto OASI 2020. Milano, Egea. 2020.

39. Sartirana M, Prenestini A, Lega F. Medical management: hostage to its own history? The case of Italian clinical directors. International Journal of Public Sector Management, 2014;27(5), 417-429.

40. Fattore, G., Longo, F., Sartirana, M II curriculum vitae dei Direttori Generali, Rapporto OASI 2013, Milano, Egea. 2013.

41. Weiss RS. Learning from Strangers: The Art and Method of Qualitative Interview Studies. New York: Free Press. 1994. 
42. Borgonovi $E$, Meda $M$, Montante $M$, Volpe V. Etica, responsabilità pubblica, imprenditorialità $e$ management. Milano: Franco Angeli. 2019.

43. Sartirana M, Currie G, Noordegraaf M. Interactive identity work of professionals in management: a hospital case study. Public Management Review, 2019;21(8), 1191-1212. 